UDC 622.834:622.27

LBC 33.124

\title{
POPPING OF CAVITIES IN THE NEAR-SURFACE COAL-BEARING STRATA OF THE DONETS BASIN
}

\author{
Andrey N. Feofanov \\ N. P. Semenenko Institute of Geochemistry, Mineralogy and Ore Formation of the National Academy \\ of Sciences of Ukraine, Kiev, Ukraine
}

\begin{abstract}
Long-term research has proved the connection between old mine workings preserved at the outcrops of coal seams and land subsidence, and sinkhole collapse. Now the causes and types of such disturbances are determined, the most dangerous of which are caves, over various types of the abandoned mine workings. In addition to it, a method has been developed and improved for assessing the hazard rate of any abandoned working (cavity) with relation to sinkholes for mining and geological conditions of the Donets Basin. At the same time, a number of cases are known when cavities wiped out due to the failure of the overlying rocks reappeared on the upper levels, threatening to generate surface depression. Thus, the former, but already liquidated cavity seemed to pop in the overlying rocks. The understudied process of cavities moving in the subsurface coal-bearing strata from the places of their original location towards the surface in the Donets Basin is described. The computation of stage-by-stage popping of relatively undestroyed mine opening (cavity) in coalbearing strata of different strength is made. The conditions and factors contributing to the popping of the remaining cavities towards the overlying levels are determined. An assumption (hypothesis) on the inevitability of popping of any abandoned working or cavity preserved on the upper levels, with a favorable combination of the affecting factors is made. The necessity for this process to be taken into account in assessing the hazard rate of the surface areas undermined by the abandoned mine workings at shallow depths due to their potential capability of making sinkholes is demonstrated. The effective reference documents regulating the procedure for assessing the hazard rate of abandoned mine workings (cavities) at shallow depths do not take into account popping of cavities that hurts correctness of the results obtained for them.
\end{abstract}

Key words: shallow depth of undermining, remained cavities and mine openings, cave roof, degree of fragmentation, affecting factors, compression zone, pop-up height, cavity-making depth.

Citation. Feofanov A.N. Popping of Cavities in the Near-Surface Coal-Bearing Strata of the Donets Basin. Natural Systems and Resources, 2020, vol. 10, no. 3, pp. 19-26. DOI: https://doi.org/10.15688/nsr.jvolsu.2020.3.3

УДК 622.834:622.27

ББК 33.124

\section{ВСПЛЫВАНИЕ ПУСТОТ \\ В ПРИПОВЕРХНОСТНОМ УГЛЕПОРОДНОМ МАССИВЕ ДОНБАССА}

\section{Андрей Николаевич Феофанов}

Институт геохимии, минералогии и рудообразования им. Н. П. Семененко НАН Украины, г. Киев, Украина

Аннотация. Многолетними исследованиями доказана связь между сохранившимися на выходах угольных пластов старыми горными выработками и повреждениями земной поверхности, расположенной над ними. В настоящее время установлены причины и виды подобных повреждений, наиболее опасными из которых являются провалы, над различными типами заброшенных горных выработок. Кроме того разработана и усовершенствована методика оценки степени опасности любой заброшенной выработки (пустоты) с точки зрения провалообразования для горно-геологических условий Донецкого угольного бассейна. Однако известен ряд случаев, когда ликвидированные за счет обрушений вышележащих пород пустоты, вновь появлялись на верхних горизонтах, угрожая образовать провал на поверхности. Таким образом, бывшая, но уже ликвидированная пустота как бы всплывает в вышележащих породах. В статье описывается малоизученный 
процесс перемещения сохранившихся в приповерхностном углепородном массиве Донбасса пустот от мест их первоначального расположения к земной поверхности. Выполнен расчет поэтапного всплывания условно сохранившейся выработки (пустоты) в многослойном породном массиве различной прочности. Определены условия и факторы, способствующие всплыванию сохранившихся пустот на вышележащие горизонты. Выдвинуто предположение (гипотеза) о неизбежности всплывания любой сохранившейся на верхних горизонтах заброшенной выработки или пустоты при благоприятном сочетании воздействующих факторов. Обоснована необходимость учета данного процесса при оценке степени опасности участков земной поверхности, подработанных заброшенными горными выработками на малых глубинах, в связи с их потенциальной способностью к провалообразованиям. В действующих нормативных документах, регламентирующих порядок оценки степени опасности заброшенных горных выработок (пустот) на малых глубинах, процесс всплывания пустот не учитывается, что отражается на корректности полученных по ним результатов.

Ключевые слова: малая глубина подработки, сохранившиеся пустоты и выработки, свод обрушения, коэффициент разрыхления, влияющие факторы, зона уплотнения, высота всплывания, провалообразующая глубина.

Цитирование. Феофанов А. Н. Всплывание пустот в приповерхностном углепородном массиве Донбасса // Природные системы и ресурсы. - 2020. - Т. 10, № 3. - С. 19-26. - DOI: https://doi.org/10.15688/ nsr.jvolsu.2020.3.3

Введение. В приповерхностном углепородном массиве (глубина до 200 м) велика вероятность сохранения пустот в заброшенных горных выработках. В свое время эти выработки (стволы, штреки, уклоны, заходки, камеры, лавы и т. п.) были задействованы в технологической цепочке по добыче и транспортировке угля. С перемещением добычи на глубину и ликвидацией отработанного участка или даже всей шахты выбывшие из эксплуатации приповерхностные выработки остаются бесхозными, полностью или частично сохраняя свои параметры. Этому способствуют оставшаяся в них крепь, небольшое горное давление на таких глубинах и повсеместное применение ленточных целиков для охраны выработок, что в основном присуще малым частным копальням периода становления угольной промышленности. С течением времени крепь выработок приходит в негодность, разрушается, и вышележащие породы начинают обрушаться. Их неконтролируемое обрушение в сохранившиеся выработки (пустоты) приводит в сдвижение приповерхностный массив (см. рис. 1). Как следствие, земная поверхность испытывает деформации в виде провалов и локальных оседаний с повышенными деформациями.

Механизм развития провала. При обрушении пород в сохранившуюся выработку в вышележащем массиве образуется свод обрушения, который из-за послойного обрушения пород постепенно перемещается к поверхности. Однако процесс обрушения может прекратиться (затухнуть). Это так называемая самоликвидация как заброшенных выработок и со- хранившихся в них пустот, так и самого процесса обрушения. А именно: обрушающиеся породы за счет разрыхления увеличиваются в объеме по сравнению с нетронутым массивом, заполняют саму пустоту и свод обрушения, что, в конце концов, приводит к его подбучиванию. Если это произойдет в массиве, то провала на поверхности не будет (см. рис. 2, $a$ ), и, наоборот, если породы не успеют подбутить свод обрушения, то он выйдет на поверхность в виде провала (см. рис. 2, б). Таким образом, с ликвидацией свода обрушения в массиве устраняется причина возможного провала - пустота, а, следовательно, и возможность новых обрушений пород.

Именно такой подход определяет существующий на сегодня алгоритм оценки степени опасности любой сохранившейся в приповерхностном массиве пустоты. Если расчеты показывают, что свод обрушения подбутится еще до выхода его на поверхность, то такая пустота не относится к разряду опасных по провалообразованию, и в дальнейшем она непринимается во внимание (исключается из оценки).

Постановка проблемы. Тем не менее, нередки случаи, когда в приповерхностном углепородном массиве обнаруживают новые, ранее не существовавшие пустоты, расположенные выше обрушенных по оси развития свода обрушения. Над вновь образованной пустотой возобновляется процесс обрушения, но так как она расположена ближе к земной поверхности, то возникает очередная угроза образования провала (см. рис. 3). Это и есть анонсированный в названии статьи процесс всплывания пустот. 
Всплывание пустоты - это появление в приповерхностном углепородном массиве новой пустоты по оси развития свода обрушения над ранее существовавшей и впоследствии ликвидированной обрушенными породами за счет их уплотнения и перераспределения.

Более детально данный процесс (или так называемый «эффект всплывающих пустот») рассмотрен в работе [1] для однослойного массива. По сути, всплывание пустот это возобновление процесса сдвижения после, казалось бы, полной ликвидации пустоты за счет заполнения ее вышележащими породами. Оценка сохранившейся выработки (пустоты) на возможность образования провала на поверхности не должна ограничиваться только лишь этапом ее самоподбучивания. Необходим учет последующего процесса всплывания. С этих позиций использование при оценке некоего общепринятого и ут- вержденного в нормативных документах, например [2], провалообразующего глубинного интервала в 80-100 м некорректно. Любая последующая пустота перемещается на меньшую высоту и возможно даже с меньшими размерами по сравнению с предыдущей. Однако это не уменьшает ее опасности, так как с каждым всплыванием она приближается к земной поверхности, что увеличивает вероятность образования провала. Количество и высота всплываний в каждом конкретном случае индивидуальны. Высота всплывания пустоты зависит в первую очередь от ее первоначальных размеров, глубины расположения от земной поверхности, прочности породных слоев и возможных провоцирующих факторов. В малопрочном породном массиве высота всплывания пустоты увеличивается. И напротив - массив из крепких пород минимизирует высоту всплывания пустоты.
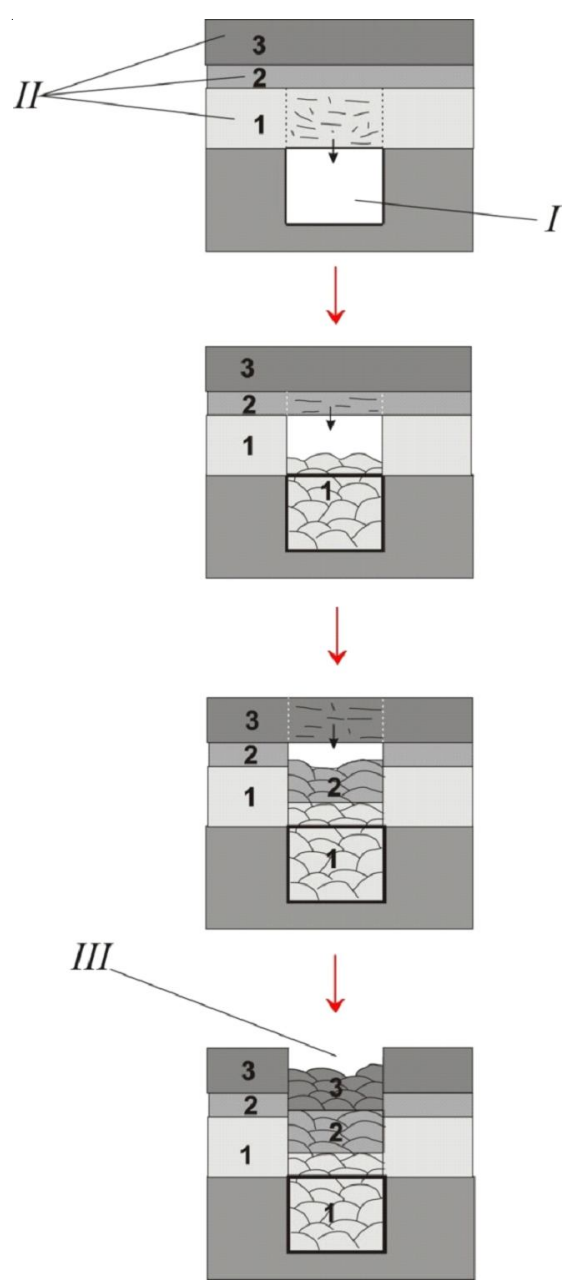

Рис. 1. Схема послойного обрушения приповерхностного массива:

I - выработка (пустота); $I I$ - вышележащая породная толща; $I I I$ - провал на поверхности $(1,2,3$ - обрушаемые слои кровли) 


\section{ЭколоГия и Биология}

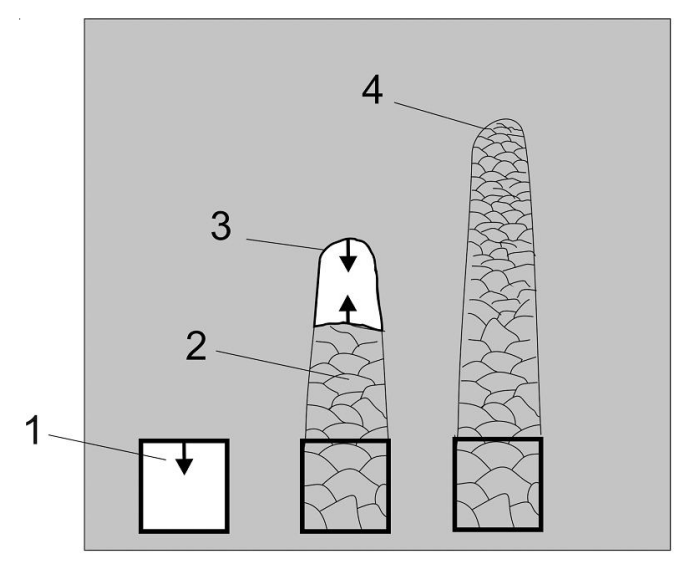

a

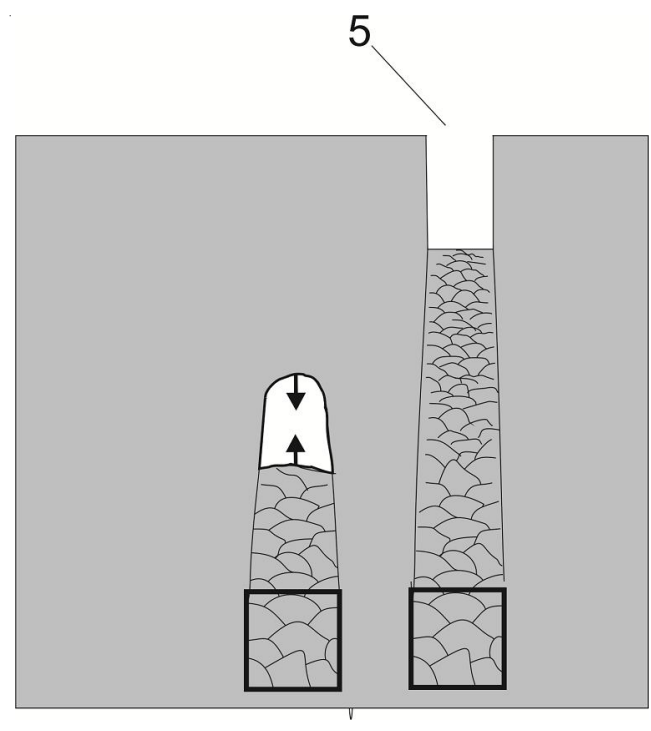

б

Рис. 2. Схема развития обрушения в массиве и провала на поверхности:

$a$ - при самоподбучивании свода обрушения в массиве; $\sigma$ - при выходе свода обрушения на поверхность

( 1 - заброшенная горная выработка; 2 - обрушенные породы; 3 - свод обрушения;

4 - подбученный свод обрушения; 5 - провал на земной поверхности)

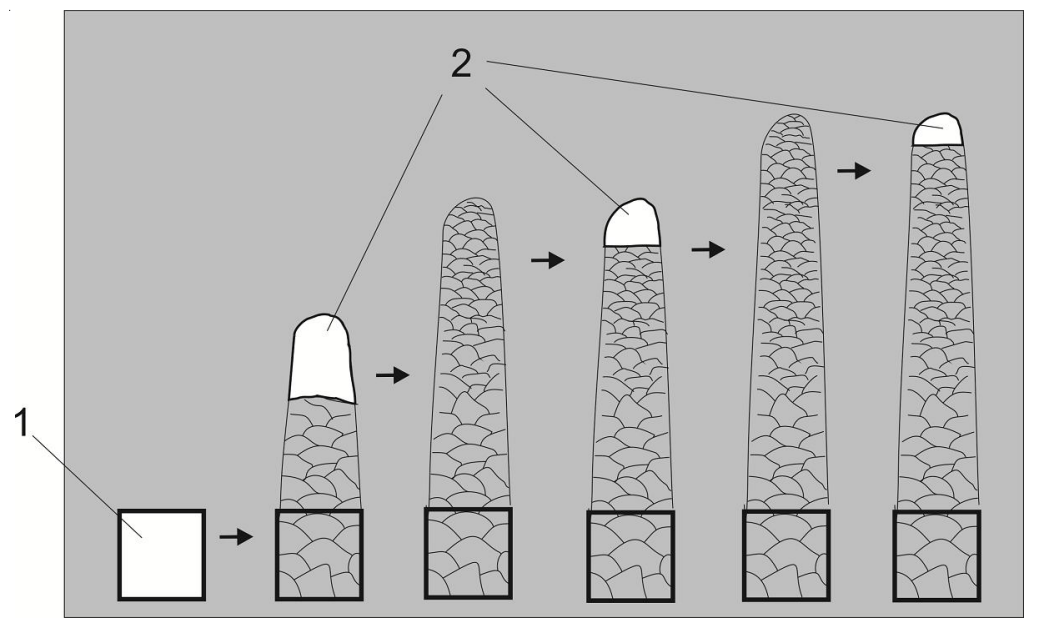

Рис. 3. Схема образования всплывающей пустоты:

1 - первоначальная «материнская» пустота (выработка); 2 - «дочерние» всплывшие пустоты 
Особенности всплывания пустот в условиях Донбасса. В действительности углепородный массив Донбасса по своей структуре представлен породными слоями, отличающимися литологической принадлежностью, мощностями, прочностью и т. д. Основные породные слои (аргиллиты, алевролиты и песчаники) переслаиваются отдельными пропластками и пластами угля, а также одиночными пластами известняка. Безусловно, наличие такого многослойного породного «пирога» сказывается на процессе обрушения заброшенных горных выработок (пустот) в горно-геологических условиях Донбасса. А так как обрушение пород является неотъемлемой частью всплывания пустот, то это привносит характерные особенности в данный процесс.

Всплывание пустоты происходит в два этапа. Вначале в сохранившуюся выработку (пустоту) обрушаются вышележащие породы. При этом образуется свод обрушения. Так как породы при обрушении разрыхляются, то они увеличиваются в объеме по сравнению с нетронутым массивом. Это приводит к тому, что перемещающийся к земной поверхности свод в определенный момент может подбутиться разрыхленными породами, ликвидировав тем самым пустоту. Нет пустоты - нет процесса обрушения.

На втором этапе подбутившие свод породы уплотняются как за счет собственного веса, так и за счет изменения гидрогеологии массива (подтопление или осушение). Известно, что некоторые разрыхленные породы карбоновой толщи Донбасса могут слеживаться до $30 \%$. В итоге в куполе свода обрушения появляется новая (дочерняя) пустота. В сравнении с первоначальной (материнской) пустотой она отличается по размерам, и степень ее опасности для земной поверхности может оказаться существенной, так как она располагается ближе к земной поверхности. Очевидно, что в пределах провалообразующего глубинного интервала, когда речь идет всего лишь о сотне метров от земной поверхности, каждый метр может оказаться решающим для выхода провала на поверхность.

Пример расчета процесса всплывания. Рассмотрим абстрактный пример обрушения вышележащих пород трехслойного породного массива в заброшенную выработку высотой 2 м. Породные слои имеют одинаковую заданную мощность 4 м, но отличаются прочностью, которую можно охарактеризовать соответствующим коэффициентом разрыхления $k_{\mathrm{p}}$. А именно: слой № 1 имеет $k_{\mathrm{p}}=1,15$, что характерно для малопрочных пород типа аргиллитов. Слой № 2 средней прочности (например, алевролит) с $k_{\mathrm{p}}=1,30$. У слоя № 3 (песчаник) $k_{\mathrm{p}}=1,60$. Используя методику оценки степени опасности приповерхностных заброшенных выработок для земной поверхности [3], рассчитаем предельную высоту развития свода обрушения (до его полного подбучивания), чередуя расположение слоев над выработкой. То есть, проводим последовательное обрушение слоев с их разлыхлением, увеличением в объеме, заполнением свободного пространства выработки и образовавшегося свода обрушения до тех пор, пока не произойдет его подбучивание (см. таблицу).

Расчеты показывают, что в данных горно-геологических условиях подбучивание свода обрушения завершается преимущественно в прочном породном слое, имеющем больший коэффициент разрыхления. Наибольшая высота развития свода обрушения составляет 8,33 м, что характерно для вариантов, когда свод вначале развивался в малопрочном и средней прочности слое и заканчивается (подбучивается) в прочном. Наименьшая 4,0 м, когда свод сразу охватывал прочные слои. Чем выше свод обрушения и, соответственно самоподбучивания, тем большее число породных слоев будет задействовано в процессе обрушения и последующем уплотнении. Тем больше может оказаться высота дочерней пустоты. На рисунке 4 представлена схема всплывания первой дочерней пустоты для горно-геологических условий, когда над сохранившейся выработкой расположены породные слои одинаковой мощности в порядке увеличения их прочности. Высота свода обрушения до его самоподбучивания составила 8,33 м (см. рис. 4, a). После уплотнения обрушенных в сохранившуюся выработку пород в куполе свода обрушения образовалась первая дочерняя пустота высотой в 3,10 м, что на $50 \%$ больше материнской пустоты и на 8,33 м ближе к земной поверхности (см. рис. $4, \sigma$ ). 
Оценка предельной высоты свода обрушения в трехслойном породном массиве

\begin{tabular}{|c|c|c|c|c|c|}
\hline \multicolumn{6}{|c|}{ Исходные данные } \\
\hline $\begin{array}{c}\text { Высота } \\
\text { выработки, м }\end{array}$ & № слоя & $\begin{array}{l}\text { Коэффициент } \\
\text { разрыхления, } k_{\mathrm{p}}\end{array}$ & \multicolumn{2}{|c|}{ Мощность, м } & $\begin{array}{c}\text { Условная } \\
\text { характеристика } \\
\end{array}$ \\
\hline 2 & $\begin{array}{l}1 \\
2 \\
3 \\
\end{array}$ & $\begin{array}{l}1,15 \\
1,30 \\
1,60 \\
\end{array}$ & \multicolumn{2}{|c|}{$\begin{array}{l}4,0 \\
4,0 \\
4,0 \\
\end{array}$} & $\begin{array}{c}\text { малопрочный } \\
\text { средней прочности } \\
\text { крепкий }\end{array}$ \\
\hline \multicolumn{6}{|c|}{ Результаты расчёта } \\
\hline \multicolumn{2}{|c|}{$\begin{array}{l}\text { Залегание слоёв } \\
\text { над выработкой }\end{array}$} & \multicolumn{2}{|c|}{$\begin{array}{c}\text { Высота подбучивания } \\
\text { свода обрушения, м }\end{array}$} & Высот & $\begin{array}{l}\text { стоты после максимальной (до } \\
\text { I обрушенных пород, м }\end{array}$ \\
\hline \multicolumn{2}{|c|}{$\begin{array}{l}1 \text { (малопрочный) } \\
2 \text { (средней прочности) } \\
3 \text { (прочный) }\end{array}$} & \multicolumn{2}{|c|}{8,33} & & 3,10 \\
\hline \multicolumn{2}{|c|}{$\begin{array}{l}1 \text { (малопрочный) } \\
3 \text { (прочный) } \\
2 \text { (средней прочности) }\end{array}$} & \multicolumn{2}{|c|}{6,33} & & 2,50 \\
\hline \multicolumn{2}{|c|}{$\begin{array}{l}2 \text { (средней прочности) } \\
3 \text { (прочный) } \\
1 \text { (малопрочный) }\end{array}$} & \multicolumn{2}{|c|}{5,33} & & 2,20 \\
\hline \multicolumn{2}{|c|}{$\begin{array}{l}2 \text { (средней прочности) } \\
1 \text { (малопрочный) } \\
3 \text { (прочный) }\end{array}$} & \multicolumn{2}{|c|}{8,33} & & 3,10 \\
\hline \multicolumn{2}{|c|}{3 (прочный) } & \multicolumn{2}{|c|}{4,00} & & 1,80 \\
\hline $\begin{array}{l}3 \text { (прочный) } \\
2 \text { (средней пр } \\
1 \text { (малопрочн }\end{array}$ & $\begin{array}{l}\text { Чности) } \\
\text { Ій) }\end{array}$ & \multicolumn{2}{|c|}{4,00} & & 1,80 \\
\hline
\end{tabular}

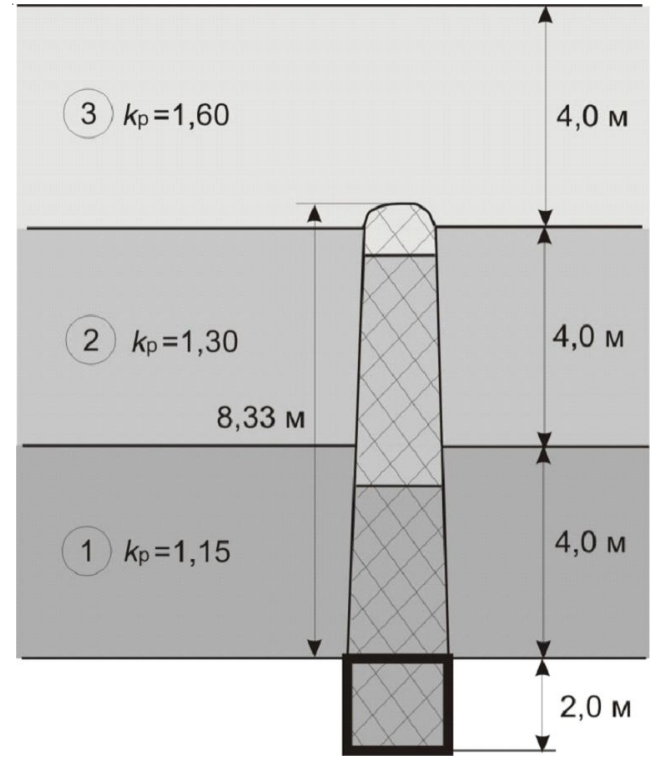

a

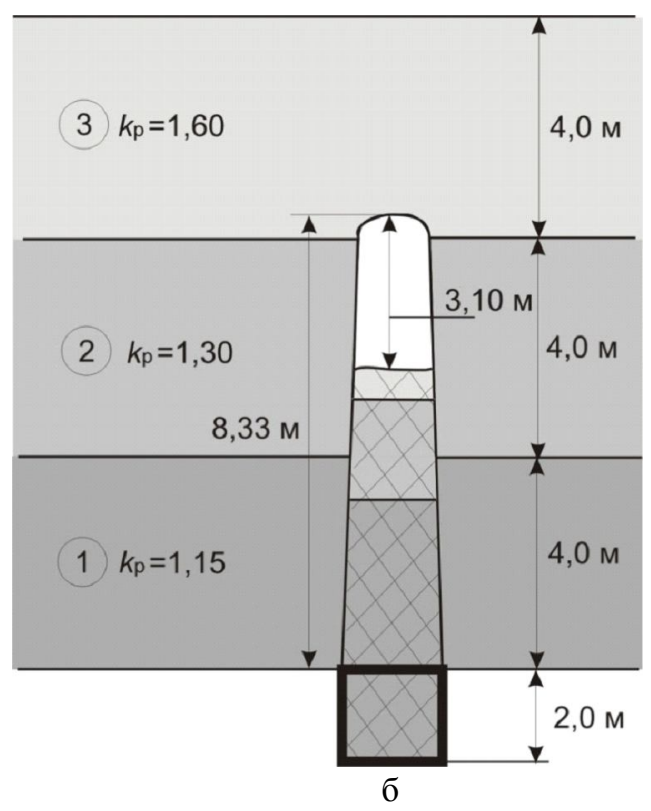

б

Рис. 4. Схема всплывания пустоты над сохранившейся выработкой:

$a$ - образование свода обрушения и его подбучивание;

$\sigma$ - образование дочерней пустоты после уплотнения обрушенных пород

Примечание. Вполне очевидно, что при другом чередовании породных слоев, изменении их мощностей и коэффициентов разрыхления на момент оценки процесс всплывания и размеры дочерней пустоты будут иными. 
Повторение и неизбежность всплывания. Дальше все повторяется. Первая всплывшая дочерняя пустота своим появлением создала условия для возобновления процесса обрушения залегающих над ней породных слоев. Они начинают обрушаться и заполнять ее. Возникает очередной свод, который с каждым обрушенным слоем перемещается к земной поверхности. Обрушенные породы, разрыхляясь, на определенной глубине могут подбутить вновь образовавшийся свод. Через некоторое время произойдет уплотнение обрушенных пород с появлением второй дочерней пустоты. И так до тех пор, пока свод обрушения не выйдет на земную поверхность с образованием провала. Исходя из этих соображений, логично предположить, что фактически любая сохранившаяся в приповерхностном породном массиве пустота благодаря процессу всплывания когдато может выйти на земную поверхность в виде провала, то есть является потенциально опасной. И эффект всплывающих пустот по сути является механизмом подтверждения этой гипотезы. В истории не только Донбасса, но любого угледобывающего региона всегда есть место случаям деформаций земной поверхности от заброшенных горных выработок, возраст которых исчисляется десятками, сотней лет и даже более. Причем, если ограничиваться расчетами только первого свода обрушения, то эти выработки (пустоты) уже давно самоликвидировались и никоим образом не должны представлять опасности для земной поверхности. Тем не менее, в тех местах появляются провалы, которых по расчетам не должно быть, так как не принимался во внимание процесс всплывания обрушенных пустот. Для этого нужны определенные условия и время.

Условия и время. Одним из таких условий является наличие примыкающего к сохранившейся выработке (пустоте) свободного пространства для приема обрушенной породной массы. Все вышеприведенные рассуждения базируются на рассмотрении пустоты, как локальной в породном массиве, что на практике является исключением. Как правило, любая горная выработка - это часть общей некогда функционировавшей сети горных выработок. С ней обязательно пересекаются или к ней примыкают другие выработки. Поэтому обрушающиеся породы будут не только накапливаться в пределах самой выработки, но и перераспределяться в свободное примыкающее пространство. То есть подбучивание первого свода обрушения будет происходить гораздо дольше, и он к тому времени успеет переместиться ближе к земной поверхности, по сравнению с тем, если бы это происходило при заполнении только сохранившейся пустоты. После подбучивания первого свода начнется усадка обрушенных пород, как за счет собственного веса, так и за счет изменения гидрогеологии массива. Поступление паводковых вод с поверхности, осушение участка или его затопление ускоряют уплотнение разрыхленного материала и его вынос в прилегающие горные выработки [4]. Свою роль могут сыграть пересечения сводом обрушения перемятых пород зон тектонической нарушенности или зон водонасыщенных песков (плывунов) наносных отложений, характерных для Западного Донбасса. В таких случаях размеры всплывшей (дочерней) пустоты оказываются больше первоначальной (материнской).Что касается времени, то абсолютная неизученность данного процесса на сегодняшний день не позволяет с определенной точностью прогнозировать время всплывания пустоты в углепородном массиве с выходом на поверхность. Учитывая многослойность карбоновой толщи и соответствующую неоднородность по прочности, а также варьирование мощности зоны выветривания, можно предположить, что скорость процесса всплывания во многом зависит от конкретной горно-геологической и горнотехнической ситуации каждого участка в отдельности. Необходимо учитывать возможность пересечения свода обрушения в массиве с сохранившимися заброшенными выработками и пустотами на верхних горизонтах. Существенную роль может оказывать техногенный фактор, а именно одновременное с процессом всплывания ведение горных работ на нижележащих горизонтах и сейсмический фактор [5]. К тому же не стоит забывать о геологии приповерхностного массива. Во-первых, это зона выветрелых, разуплотненных пород, где законы упругих деформаций не работают. Причем мощность этой зоны в различных по степени метамор- 
физма угля (катагенеза пород) районах Донбасса весьма неоднородна. Во-вторых, при наличии крепких породных слоев (песчаник, известняк), встречающихся преимущественно в Восточном Донбассе, процесс всплывания купируется на неопределенное время (до разрушения экранирующего слоя). Фактически все эти нюансы являются направлениями последующих исследований процесса всплывания пустот.

Заключение. Для получения адекватной оценки экологической безопасности подработанных угленосных территорий необходимо учитывать процесс всплывания пустот, сохранившихся в заброшенных горных выработках приповерхностной углепородной толщи с учетом влияния горно-геологических и горнотехнических факторов в каждом конкретном случае.

\section{СПИСОК ЛИТЕРАТУРЫ}

1. Феофанов, А. Н. Всплывающие пустоты / А. Н. Феофанов // Збірник наукових праць Національного гірничого університету - 2019. - № 59. C. $77-86$.

2. Феофанов, А. Н. Критические замечания на некоторые пункты «Правил подработки. ..» / А. Н. Феофанов // Уголь Украины. - 2017. - № 1-2. - С. 9-13.

3. Феофанов, А. Н. Оценка возможности провала земной поверхности / А. Н. Феофанов // Уголь Украины. -2015. - № 11. - С. 7-12.

4. Феофанов, А. Н. Переоценка влияния факторов на процесс активизации провалообразований / А. Н. Феофанов // Наукові праці УкрНДМІ-
НАН України: зб. наук. пр. - Донецьк,2009. - № 5. C. $18-32$.

5. Феофанов, А. Н. Сейсмическая активность как провоцирующий фактор активизации процесса сдвижения / А. Н. Феофанов // Наукові праці УкрНДМІ НАН України: зб. наук. пр. - Донецьк, 2009. - № 5. - С. 33-45.

\section{REFERENCES}

1. Feofanov A.N. Vsplyvajushchie pustoty [Popping-Up Cavities]. Zbirnyk naukovyh prats Natsionalnoho girnychoho universytetu [Collection of Scientific Labours of the National Mining University], 2019, no. 59, pp. 77-86.

2. Feofanov A.N. Kriticheskie zamechanija na nekotorye punkty "Pravil podrabotki..." [Critical Comments on Some of the Items of Regulations for Undermining...]. Ugol Ukrainy [Coal of Ukraine], 2017, no. 1-2, pp. 9-13.

3. Feofanov A.N. Otsenka vozmozhnosti provala zemnoj poverhnosti [Assessment of the Possibility of Caving on the Surface]. Ugol Ukrainy [Coal of Ukraine], 2015, no. 11, pp. 7-12.

4. Feofanov A.N. Pereotsenka vlijanija faktorov na protsess aktivizatsii provaloobrazovanij [Reassessment of the Influence of Factors on Caving Activation Process]. Naukovi pratsi UkrNDMI NAN Ukrainy: zb. nauk. pr. [Transactions of UkrNDMI NAN Ukraine]. Donetsk, 2009, no. 5, pp. 18-32.

5. Feofanov A.N. Seismicheskaija aktivnost kak provotsirujushchij factor aktivizatsii protsessa sdvizhenija [Seismic Activity as Promoter of Ground Movement Activation]. Naukovi pratsi UkrNDMI NAN Ukrainy: zb. nauk. pr. [Transactions of UkrNDMI NAN Ukraine]. Donetsk, 2009, no. 5, pp. 33-45.

\section{Information About the Author}

Andrey N. Feofanov, Candidate of Sciences (Engineering), Senior Researcher, Department of Geological and Geochemical Survey, N. P. Semenenko Institute of Geochemistry, Mineralogy and Ore Formation of the National Academy of Sciences of Ukraine, Prosp. Akademika Palladina, 34, 03142 Kiev, Ukraine, andrei.feo@mail.ru

\section{Информация об авторе}

Андрей Николаевич Феофанов, кандидат технических наук, старший научный сотрудник, старший научный сотрудник отдела геологических и геохимических исследований института геохимии, минералогии и рудообразования им. Н.П. Семененко НАН Украины, просп. Академика Палладина, 34, 03142 г. Киев, Украина, andrei.feo@mail.ru 